\title{
Differences in esophageal cancer characteristics and survival between Chinese and Caucasian patients in the SEER database
}

This article was published in the following Dove Press journal:

OncoTargets and Therapy

19 October 2016

Number of times this article has been viewed

Min-Qiang Lin, ${ }^{1}, *$ Yue-Ping $\mathrm{Li},{ }^{2, *}$ San-Gang Wu, ${ }^{3}$ Jia-Yuan Sun, ${ }^{4}$ Huan-Xin Lin, ${ }^{4}$ ShiYang Zhang, ${ }^{5}$ Zhen-Yu He ${ }^{4}$

'Department of Scientific Management, The First Affiliated Hospital of Xiamen University, Xiamen, ${ }^{2}$ Public Health School of Fujian Medical University, Fuzhou, ${ }^{3}$ Department of Radiation Oncology, The First Affiliated Hospital of Xiamen University, Xiamen, ${ }^{4}$ Department of Radiation Oncology, State Key Laboratory of Oncology in South China, Collaborative Innovation Center of Cancer Medicine, Sun Yat-sen University Cancer Center, Guangzhou, ${ }^{5}$ Department of Hospital Infection Management, The First Affiliated Hospital of Xiamen University, Xiamen, People's Republic of China

*These authors contributed equally to this work

Correspondence: Shi-Yang Zhang Department of Hospital Infection Management, The First Affiliated Hospital of Xiamen University, 55 Zhenhai Road, Xiamen 361003, People's Republic of China

Tel +86592 2139369

Fax +86592 2137229

Email18859938889@I63.com

Zhen-Yu He

Department of Radiation Oncology,

State Key Laboratory of Oncology in

South China, Collaborative Innovation

Center of Cancer Medicine, Sun Yat-sen

University Cancer Center, 65I Dongfeng

Road East, Guangzhou 5I 0060, People's

Republic of China

Tel +862087343543

Fax +862087343392

Email hezhy@sysucc.org.cn
Background: To compare the clinicopathologic characteristics and survival of Chinese and Caucasian esophageal cancer (EC) patients residing in the US, using a population-based national registry (Surveillance Epidemiology and End Results [SEER]) database.

Methods: Patients with EC were identified from the SEER program from 1988 to 2012. Kaplan-Meier survival methods and Cox proportional hazards regression were performed.

Results: A total of 479 Chinese and 35,748 Caucasian EC patients were identified. Compared with Caucasian patients, the Chinese patients had a later year of diagnosis, remained married after EC was diagnosed, had esophageal squamous cell carcinomas (ESCCs) more frequently, had tumors located in the upper-third and middle-third of the esophagus more frequently, and fewer patients presented with poorly/undifferentiated EC and underwent cancer-directed surgery. In Chinese patients, the incidence of esophageal adenocarcinomas (EACs) increased from 1988 to 2012 ( $P=0.054)$, and the majority of EAC patients had tumors located in the lower thoracic esophagus. The overall survival (OS) was not significantly different between Chinese and Caucasian patients $(P=0.767)$. However, Chinese patients with ESCC had a significantly better OS when compared to their Caucasian counterparts, whereas there was no significant difference in the OS between Chinese and Caucasian patients with EAC.

Conclusion: The presenting demographic features, tumor characteristics, and outcomes of EC patients differed between Chinese and Caucasian patients residing in the US. Chinese patients diagnosed with EAC tended to share similar clinical features with their Caucasian counterparts, and the Chinese patients with ESCC had better OS than their Caucasian counterparts.

Keywords: esophageal cancer, Chinese, Caucasian, SEER, survival

\section{Introduction}

Previous studies have demonstrated that morbidities and survival rates differ among races. ${ }^{1-3}$ Esophageal squamous cell carcinoma (ESCC) is the most common histologic type of esophageal cancer (EC) in Asian population. Indeed, about half of all EC-related deaths were found in People's Republic of China and nearly all are due to ESCC. ${ }^{4}$ In recent years, the incidence of esophageal adenocarcinoma (EAC) has increased rapidly in Western countries, such as the US, and EAC is now the most common histologic subtype in these countries. ${ }^{5-8}$ The epidemiology and survival of patients with ESCC and EAC have diverse characteristics, which are closely correlated with genetic profile, society, lifestyle, economy, culture, environment, and dietary habits. ${ }^{9,10}$

Along with the progress of international exchange, an increasing number of Chinese migrate to the US, accounting for a majority of Asian immigrants. ${ }^{11}$ Due to geographic migration, Chinese immigrants tend to have similar lifestyles and dietary 
habits as Western residents. ${ }^{12}$ A nationwide analysis of the demographic, clinicopathologic, and outcomes related to EC in the population-based Surveillance, Epidemiology, and End Results (SEER) database for the Chinese-Caucasian cohort has not been undertaken. Therefore, the purpose of this study was to compare demographic, clinicopathologic, and survival for Chinese and Caucasian EC patients residing in the US using data from the SEER program.

\section{Patients and methods}

Patients with a diagnosis of ESCC or EAC were identified using the SEER database from 1988 to 2012 using the International Classification of Disease for Oncology, Third Edition (ICD-O-3). All patients identified as Caucasian and Chinese residing in the US with a primary diagnosis of thoracic ESCC or EAC were included in the analysis. Patients with other racial subgroups and other histologic types were excluded. The permission was obtained to access research data files with the reference number 11252-Nov 2014. ${ }^{13}$ This study was approved by the Ethics Committee of the First Affiliated Hospital of Xiamen University and Sun Yat-sen University Cancer Center. Informed consent is not required for use of SEER database data, as was confirmed by these ethics committees.

The following demographic, clinicopathologic, and outcomes data were collected from the SEER program: year of study, race, sex, age, histologic type, tumor location, histologic grade, SEER stage, marital status, and treatment strategies, including cancer-directed surgery (CDS) and radiotherapy. Vital status, including cause of death and the duration of follow-up, was recorded.

The $\chi^{2}$ and Fisher's exact probability tests were used to analyze the differences between qualitative data. Univariate and multivariate Cox regression analyses were generated to analyze risk factors for overall survival (OS). Multivariate analysis was performed for factors which were significantly associated with OS based on univariate analysis. Calculation of survival rates was plotted by the Kaplan-Meier method and compared using the log-rank test. All data were analyzed with a SPSS statistical software package (version 21.0; IBM Corporation, Armonk, NY, USA). A value of $P<0.05$ was considered statistically significant.

\section{Results}

A total of 36,227 EC patients were identified. Among these patients, the majority $(98.7 \%$ [35,748/36,227]) were Caucasian, and 1.3\% (479/36,227) were Chinese. The demographics, clinical characteristics, and outcomes of all patients are shown in Table 1 . There were significant differences in the demographics, clinical characteristics, and treatments between the Chinese and Caucasian patients. The Chinese patients had a later year of diagnosis and remained married after EC was diagnosed. The majority of Chinese patients (81.8\% [392/479]) had ESCC, and $67.7 \%(24,206 / 35,748)$ of Caucasian patients had EAC. In addition, more Chinese patients had tumors located in the upper-third and middle-third of the esophagus, and 73.6\% of Caucasian patients had lower-third EC. A smaller proportion of Chinese presented with poorly/undifferentiated disease $(45.3 \%$ vs $51.8 \%, P=0.006)$ and underwent CDS (23.2\% vs $31.4 \%, P<0.001)$, and a larger proportion of Chinese presented with SEER regional stage $(41.6 \%$ vs $35 \%, P=0.010)$.

The demographics and tumor characteristics of ESCC and EAC are shown in Table 2. In Chinese patients, the incidence of EAC increased from 1988 to $2012(P=0.054)$. Most of the EAC patients $(81.6 \%$ [71/87]) had tumors located in the lower thoracic esophagus, 50\% (36/72) of EAC patients had SEER distant stage, and only $31.8 \%$ of patients had distant stage of ESCC. In Caucasian patients, there were significant differences in the demographics, clinical characteristics, and treatments between the ESCC and EAC patients.

Kaplan-Meier analysis demonstrated no difference in OS rates between Chinese and Caucasian patients $(P=0.760)$; however, the results differed when stratified by histologic type. Chinese patients with ESCC had a significantly better OS than Caucasian patients ( $P=0.001$; Figure $1 \mathrm{~A})$. In contrast, Caucasian patients with EAC had a significantly better OS compared to Chinese patients ( $P=0.004$; Figure 1B).

The results of the univariate analysis on OS are shown in Table 3. The OS was not significantly different between Chinese and Caucasian patients $(P=0.767)$. Chinese race was associated with a better OS in patients with $\operatorname{ESCC}(P=0.001)$. Caucasian race was associated with a better OS in patients with EAC $(P=0.006)$ (Table S1).

The multivariate Cox proportional hazards regression model was adjusted for year of study, age, sex, tumor location, histologic grade, SEER stage, marital status, surgical treatment, and radiotherapy (Table 4). Chinese race was independently associated with a better OS in patients with ESCC compared to Caucasian patients (hazard ratio $[\mathrm{HR}]=1.330 ; 95 \%$ confidence interval $[\mathrm{CI}]=1.159-1.527$, $P<0.001)$. There was no significant difference in OS between Chinese and Caucasian patients with $\mathrm{EAC}(\mathrm{HR}=0.853 ; 95 \%$ $\mathrm{CI}=0.642-1.132, P=0.271)$ (Table S2).

Stratifying analysis according to race was performed (Tables 3 and 4). Chinese patients with ESCC had a better OS than EAC patients based on univariate $(P=0.015)$ and 
Table I Clinicopathologic characteristics of Chinese and Caucasian patients with esophageal cancer residing in the US from the SEER database

\begin{tabular}{|c|c|c|c|c|}
\hline Characteristic & $\mathbf{N}(\%)$ & Chinese (\%) & Caucasian (\%) & $P$-value \\
\hline Years of study & & & & $<0.001$ \\
\hline $1988-1992$ & $2,676(7.4)$ & $48(10.0)$ & $2,628(7.4)$ & \\
\hline $1993-1997$ & $3,886(10.7)$ & $77(16.1)$ & $3,809(10.7)$ & \\
\hline $1998-2002$ & $7,572(20.9)$ & $102(21.3)$ & $7,470(20.9)$ & \\
\hline $2003-2007$ & $10,447(28.8)$ & $123(25.7)$ & $10,324(28.9)$ & \\
\hline $2008-2012$ & II,646 (32.I) & $129(26.9)$ & 11,517 (32.2) & \\
\hline Age, years & & & & 0.106 \\
\hline$\leq 60$ & $9,881(27.3)$ & II $5(24.0)$ & $9,766(27.3)$ & \\
\hline$>60$ & $26,346(72.7)$ & $364(76.0)$ & $25,982(72.7)$ & \\
\hline Sex & & & & 0.209 \\
\hline Male & $28,263(78.0)$ & $385(80.4)$ & $27,878(78.0)$ & \\
\hline Female & $7,964(22.0)$ & $94(19.6)$ & $7,870(22.0)$ & \\
\hline Tumor location & & & & $<0.001$ \\
\hline Upper thoracic & $2,392(6.6)$ & $72(15.0)$ & $2,320(6.5)$ & \\
\hline Middle thoracic & $7,319(20.2)$ & $198(4 \mid .3)$ & $7,121(19.9)$ & \\
\hline Lower thoracic & $26,516(73.2)$ & $209(43.6)$ & $26,307(73.6)$ & \\
\hline Tumor histology & & & & $<0.00$ I \\
\hline Squamous & II,934 (32.9) & $392(81.8)$ & I I,542 (32.3) & \\
\hline Adenocarcinoma & $24,293(67.1)$ & $87(18.2)$ & $24,206(67.7)$ & \\
\hline Grade $(n=30,42 I)$ & & & & 0.006 \\
\hline Well-differentiated & $1,896(6.2)$ & $19(4.8)$ & I,877 (6.3) & \\
\hline Moderately differentiated & $12,787(42.0)$ & $196(49.9)$ & $|2,59|(4 \mid .9)$ & \\
\hline Poorly/undifferentiated & $15,738(51.7)$ & $178(45.3)$ & $15,560(5 \mid .8)$ & \\
\hline SEER stage $(n=31,867)$ & & & & 0.010 \\
\hline Localized stage & $9,155(28.7)$ & $96(23.5)$ & $9,059(28.8)$ & \\
\hline Regional stage & II,I $177(35.1)$ & $170(4 \mid .6)$ & I I,007 (35.0) & \\
\hline Distant stage & II,535 (36.2) & $143(35.0)$ & II,392 (36.2) & \\
\hline Surgery $(n=35,7 \mid 7)$ & & & & $<0.001$ \\
\hline No & $24,557(68.8)$ & $365(76.8)$ & $24,192(68.6)$ & \\
\hline Yes & $11,160(31.2)$ & $110(23.2)$ & II,050 (3।.4) & \\
\hline Radiotherapy $(n=35,132)$ & & & & 0.109 \\
\hline No & $|5,6| 2(44.4)$ & $190(40.8)$ & $15,422(44.5)$ & \\
\hline Yes & $19,520(55.6)$ & $276(59.2)$ & $19,244(55.5)$ & \\
\hline Marital status $(\mathrm{n}=34,85 \mathrm{I})$ & & & & $<0.001$ \\
\hline Married & $26,815(76.9)$ & $393(83.8)$ & $26,422(76.8)$ & \\
\hline Not married & $8,036(23.1)$ & $76(16.2)$ & $7,960(23.2)$ & \\
\hline Mortality & & & & 0.737 \\
\hline Alive & $6,295(17.4)$ & $86(18.0)$ & $6,209(17.4)$ & \\
\hline Dead & $29,932(82.6)$ & $393(82.0)$ & $29,539(82.6)$ & \\
\hline Esophageal cancer-related death & & & & 0.130 \\
\hline No & $13,378(36.9)$ & $161(33.6)$ & $13,217(37.0)$ & \\
\hline Yes & $22,849(63.1)$ & $318(66.4)$ & $22,531(63.0)$ & \\
\hline
\end{tabular}

Abbreviation: SEER, Surveillance Epidemiology and End Results.

multivariate $(P<0.001)$ analyses (Figure 2A). In Caucasian population, EAC patients had a better OS than ESCC patients based on univariate analysis $(P<0.001$; Figure $2 \mathrm{~B})$, but not in multivariate analysis $(P=0.996)$.

\section{Discussion}

In the Chinese population, ESCC was the dominant type of $\mathrm{EC},{ }^{4}$ whereas a majority of the American population were EAC, especially for Caucasians from the US. ${ }^{5,6}$ Currently, comparative studies analyzing the morbidity and prognosis between the Chinese and Caucasians populations have been rarely reported. In this study, the SEER database was used for a comparative analysis. It was found that the Chinese and Caucasians patients with EC have different clinical features and outcomes. Nevertheless, ethnicity exerts no effect upon the survival of all EC patients. Interestingly, subgroup analysis demonstrated that survival difference exists among different populations with diverse histologic 
Table 2 Clinicopathologic characteristics of ESCC and EAC patients between Chinese and Caucasians residing in the US from the SEER database

\begin{tabular}{|c|c|c|c|c|c|c|c|c|}
\hline \multirow[t]{2}{*}{ Characteristic } & \multicolumn{4}{|l|}{ Chinese } & \multicolumn{4}{|l|}{ Caucasian } \\
\hline & $\mathbf{N}(\%)$ & ESCC (\%) & EAC (\%) & $\overline{P \text {-value }}$ & $\mathbf{N}(\%)$ & ESCC (\%) & EAC (\%) & $P$-value \\
\hline Years of study & & & & 0.054 & & & & $<0.001$ \\
\hline $1988-1992$ & $48(10.0)$ & $42(10.7)$ & $6(6.9)$ & & $2,628(7.4)$ & $1,416(12.3)$ & $1,212(5.0)$ & \\
\hline $1993-1997$ & $77(16.1)$ & $62(15.8)$ & $15(17.2)$ & & 3,809 (I0.7) & I,684 (I4.6) & $2,125(8.8)$ & \\
\hline $1998-2002$ & $102(21.3)$ & $92(23.5)$ & $10(11.5)$ & & $7,470(20.9)$ & $2,545(22.0)$ & $4,925(20.3)$ & \\
\hline 2003-2007 & $123(25.7)$ & $98(25.0)$ & $25(28.7)$ & & $10,324(28.9)$ & $2,980(25.8)$ & $7,344(30.3)$ & \\
\hline $2008-2012$ & $129(26.9)$ & $98(25.0)$ & $31(35.6)$ & & $1 \mathrm{I}, 517(32.2)$ & $2,917(25.3)$ & $8,600(35.5)$ & \\
\hline Age, years & & & & 0.806 & & & & $<0.001$ \\
\hline$\leq 60$ & II 5 (24.0) & $95(24.2)$ & $20(23.0)$ & & $9,766(27.3)$ & $2,505(21.7)$ & $7,261(30.0)$ & \\
\hline$>60$ & $364(76.0)$ & $297(75.8)$ & $67(77.0)$ & & $25,982(72.7)$ & $9,037(78.3)$ & $16,945(70.0)$ & \\
\hline Sex & & & & 0.983 & & & & $<0.001$ \\
\hline Male & $385(80.4)$ & $315(80.4)$ & $70(80.5)$ & & $7,870(22.0)$ & $4,525(39.2)$ & $3,345(13.8)$ & \\
\hline Female & $94(19.6)$ & $77(19.6)$ & 17 (19.5) & & $27,878(78.0)$ & $7,017(60.8)$ & $20,86 I(86.2)$ & \\
\hline Tumor location & & & & $<0.001$ & & & & $<0.001$ \\
\hline Upper thoracic & 72 (I5.0) & $69(17.6)$ & $3(3.4)$ & & $2,320(6.5)$ & $2,000(I 7.3)$ & $320(1.3)$ & \\
\hline Middle thoracic & $198(4 \mid .3)$ & $185(47.2)$ & $13(14.9)$ & & $7,121)(19.9)$ & $5,115(44.3)$ & $2,006(8.3)$ & \\
\hline Lower thoracic & $209(43.6)$ & 138 (35.2) & 71 (8I.6) & & 26,307 (73.6) & 4,427 (38.4) & $21,880(90.4)$ & \\
\hline Grade & & & & 0.021 & & & & $<0.001$ \\
\hline Well-differentiated & $19(4.8)$ & $16(5.0)$ & $3(4.2)$ & & $\mathrm{I}, 877(6.3)$ & $585(6.1)$ & $1,292(6.3)$ & \\
\hline Moderately differentiated & $196(49.9)$ & $170(53.0)$ & $26(36.1)$ & & $|2,59|(4 \mid .9)$ & $4,336(44.9)$ & $8,255(40.5)$ & \\
\hline Poorly/undifferentiated & $178(45.3)$ & $135(42.0)$ & $43(59.7)$ & & $\mid 5,560(5 \mid .8)$ & $4,727(49.0)$ & $10,833(53.2)$ & \\
\hline SEER stage & & & & 0.008 & & & & $<0.001$ \\
\hline Localized stage & $96(23.5)$ & $86(25.5)$ & $10(13.9)$ & & $9,059(28.8)$ & $3,132(32.4)$ & $5,927(27.2)$ & \\
\hline Regional stage & $170(4 \mid .6)$ & 144 (42.7) & $26(36.1)$ & & II,007 (35.0) & $3,645(37.7)$ & $7,362(33.8)$ & \\
\hline Distant stage & $143(35.0)$ & $107(31.8)$ & $36(50.0)$ & & II,392 (36.2) & $2,892(29.9)$ & $8,500(39.0)$ & \\
\hline Surgery & & & & 0.546 & & & & $<0.001$ \\
\hline No & $365(76.8)$ & $296(76.3)$ & $69(79.3)$ & & $24,192(68.6)$ & $8,84 \mid(77.7)$ & $|5,35|(64.3)$ & \\
\hline Yes & $110(23.2)$ & $92(23.7)$ & $18(20.7)$ & & II,050 (31.4) & $2,540(22.3)$ & $8,510(35.7)$ & \\
\hline Radiotherapy & & & & 0.009 & & & & $<0.001$ \\
\hline No & $190(40.8)$ & I 46 (38.0) & $44(53.7)$ & & $15,422(44.5)$ & $4,20 \mathrm{I}(37.8)$ & $\mid \mathrm{I}, 22 \mathrm{|}(47.7)$ & \\
\hline Yes & $276(59.2)$ & $238(62.0)$ & $38(46.3)$ & & $19,244(55.5)$ & $6,923(62.2)$ & $|2,32|(52.3)$ & \\
\hline Marital status & & & & 0.089 & & & & $<0.001$ \\
\hline Married & $393(83.8)$ & 327 (85.2) & $66(77.6)$ & & $26,422(76.8)$ & $8,252(74.3)$ & $18,170(78.1)$ & \\
\hline Not married & $76(16.2)$ & $57(14.8)$ & $19(22.4)$ & & $7,960(23.2)$ & $2,854(25.7)$ & 5,106 (21.9) & \\
\hline
\end{tabular}

Abbreviations: ESCC, esophageal squamous cell carcinoma; EAC, esophageal adenocarcinoma; SEER, Surveillance Epidemiology and End Results.
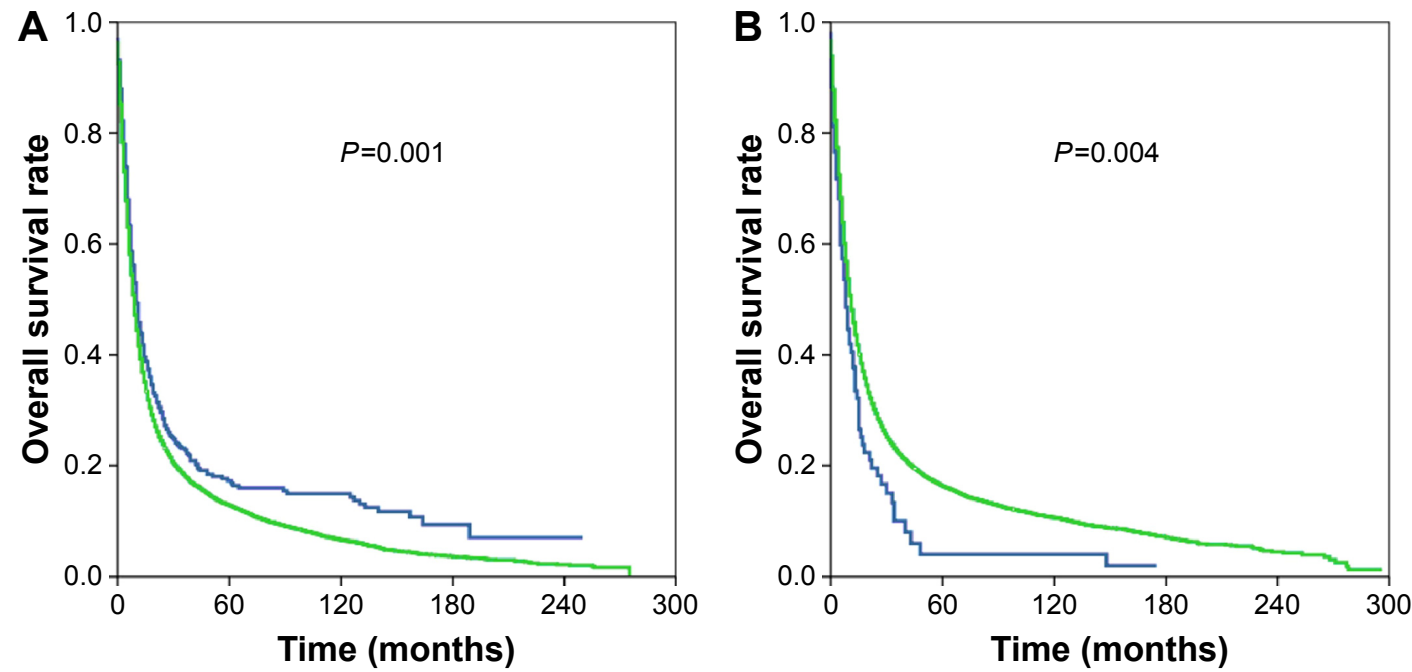

$\neg$ Chinese $\sim$ Caucasian

Figure I Overall survival of esophageal cancer in Chinese and Caucasian patients.

Notes: (A) Chinese patients with esophageal squamous cell carcinomas showing significantly better overall survival than Caucasian patients $(P=0.00 \mathrm{I})$. (B) Caucasian patients with esophageal adenocarcinoma showing significantly better overall survival compared to Chinese patients $(P=0.004)$. 
Table 3 Univariate Cox analysis of overall survival of patients with esophageal cancer

\begin{tabular}{|c|c|c|c|c|c|c|c|c|c|}
\hline \multirow[t]{2}{*}{ Characteristic } & \multicolumn{3}{|c|}{ Entire cohort } & \multicolumn{3}{|c|}{ Chinese } & \multicolumn{3}{|c|}{ Caucasian } \\
\hline & HR & $95 \% \mathrm{Cl}$ & $P$-value & HR & $95 \% \mathrm{Cl}$ & $P$-value & HR & $95 \% \mathrm{Cl}$ & P-value \\
\hline Years of study (continuous variable) & 0.986 & $0.982-0.985$ & $<0.001$ & 0.975 & $0.960-0.990$ & $<0.001$ & 0.984 & $0.982-0.985$ & $<0.001$ \\
\hline Age, years (continuous variable) & 1.019 & $1.018-1.020$ & $<0.001$ & 1.015 & $1.006-1.024$ & $<0.001$ & 1.020 & $1.018-1.021$ & $<0.001$ \\
\hline \multicolumn{10}{|l|}{ Sex } \\
\hline Male & 1 & & & I & & & I & & \\
\hline Female & 1.074 & $1.045-1.103$ & $<0.001$ & 1.043 & $0.811-1.341$ & 0.744 & 1.074 & $1.045-1.104$ & $<0.001$ \\
\hline \multicolumn{10}{|l|}{ Tumor location } \\
\hline Upper thoracic & I & & & I & & & I & & \\
\hline Middle thoracic & 0.985 & $0.937-1.035$ & 0.551 & 0.826 & $0.610-1.119$ & 0.218 & 0.991 & $0.942-1.042$ & $0.7 I I$ \\
\hline Lower thoracic & 0.843 & $0.806-0.881$ & $<0.001$ & 0.917 & $0.678-1.240$ & 0.574 & 0.842 & $0.804-0.881$ & $<0.001$ \\
\hline \multicolumn{10}{|l|}{ Tumor histology } \\
\hline Squamous & 1 & & & I & & & I & & \\
\hline Adenocarcinoma & 0.855 & $0.835-0.876$ & $<0.001$ & 1.372 & $1.064-1.769$ & 0.015 & 0.846 & $0.829-0.870$ & $<0.001$ \\
\hline \multicolumn{10}{|l|}{ Grade } \\
\hline Well-differentiated & I & & & I & & & I & & \\
\hline Moderately differentiated & $\mathrm{I} .324$ & $1.251-1.400$ & $<0.001$ & 1.025 & $0.603-1.743$ & 0.927 & 1.328 & $1.255-1.406$ & $<0.001$ \\
\hline Poorly/undifferentiated & 1.668 & I.578-I.764 & $<0.001$ & 1.421 & $0.836-2.416$ & 0.195 & 1.672 & $1.581-1.768$ & $<0.001$ \\
\hline \multicolumn{10}{|l|}{ SEER stage } \\
\hline Localized stage & 1 & & & I & & & I & & \\
\hline Regional stage & 1.379 & $1.335-1.424$ & $<0.001$ & 1.101 & $0.830-1.462$ & 0.504 & 1.383 & I.339-I.428 & $<0.001$ \\
\hline Distant stage & 2.902 & $2.810-2.996$ & $<0.001$ & 1.909 & $1.432-2.543$ & $<0.001$ & 2.921 & $2.828-3.017$ & $<0.001$ \\
\hline \multicolumn{10}{|l|}{ Surgery } \\
\hline No & I & & & I & & & I & & \\
\hline Yes & 0.373 & $0.363-0.383$ & $<0.001$ & 0.487 & $0.38 I-0.624$ & $<0.001$ & 0.371 & $0.36 I-0.38 I$ & $<0.001$ \\
\hline \multicolumn{10}{|l|}{ Radiotherapy } \\
\hline No & 1 & & & I & & & I & & \\
\hline Yes & 0.824 & $0.805-0.844$ & $<0.001$ & 0.830 & $0.676-1.020$ & 0.076 & 0.824 & $0.805-0.844$ & $<0.001$ \\
\hline \multicolumn{10}{|l|}{ Marital status } \\
\hline Married & 1 & & & I & & & 1 & & \\
\hline Not married & 1.095 & $1.066-1.126$ & $<0.001$ & 1.129 & $0.864-1.474$ & 0.374 & 1.095 & $1.065-1.126$ & $<0.001$ \\
\hline \multicolumn{10}{|l|}{ Ethnicity } \\
\hline Chinese & I & & & - & & & - & & \\
\hline Caucasian & 1.015 & $0.919-1.122$ & 0.767 & - & - & - & - & - & - \\
\hline
\end{tabular}

Abbreviations: SEER, Surveillance Epidemiology and End Results; HR, hazard ratio; $\mathrm{Cl}$, confidence interval.

types of EC. In addition, the survival rate of Chinese ESCC patients was higher compared with Caucasians; however, the same phenomenon was not demonstrated with respect to EAC.

Based on the analysis, tumor location and histologic type were the major differences between the Chinese and Caucasian races. Caucasian patients were mainly diagnosed with lower thoracic EC and EAC, whereas middle and upper thoracic EC and ESCC were mainly observed in the Chinese population, which is consistent with most previous findings. ${ }^{14-16}$ In the Western countries, Barrett's esophagus is the primary risk factor for EAC. ${ }^{17}$ Nevertheless, among 5,041 EC patients from a high-risk EC region in People's Republic of China, 217 patients (4.3\%) were diagnosed with EAC, and only 4.6\% (10/217) of these patients had Barrett's esophagus. ${ }^{18}$ In another epidemiologic study conducted in People's Republic of China, only $1.5 \%$ of 4,422 EC patients were diagnosed with EAC. ${ }^{19}$
The current study showed that the prevalence of EAC was $18.2 \%$ in Chinese immigrants, which was significantly higher compared with the Chinese counterparts who reside in People's Republic of China. In addition, the incidence of EAC in Chinese patients with EC tended to gradually ascend between 1988 and $2012(P=0.054)$. Moreover, the location of EAC was similar to the US counterparts, predominantly involving the lower thoracic EC. This phenomenon probably results from the fact that the Chinese immigrants become more accustomed to the life and dietary habits of local residents in the US.

It was also demonstrated that the age of onset of ESCC and EAC significantly differed in the Caucasian population; however, the histologic type of EC was not correlated with the age of onset $(P=0.806)$. Due to the lack of data with regard to migration time in the SEER database, it was difficult to evaluate the difference in EC morbidity in the Chinese race based upon the duration of dietary alteration. 
Table 4 Multivariate Cox analysis of overall survival of patients with esophageal cancer

\begin{tabular}{|c|c|c|c|c|c|c|c|c|c|}
\hline \multirow[t]{2}{*}{ Characteristic } & \multicolumn{3}{|c|}{ Entire cohort } & \multicolumn{3}{|c|}{ Chinese } & \multicolumn{3}{|c|}{ Caucasian } \\
\hline & HR & $95 \% \mathrm{CI}$ & $P$-value & HR & $95 \% \mathrm{Cl}$ & $P$-value & HR & $95 \% \mathrm{Cl}$ & $P$-value \\
\hline Years at study (continuous variable) & 0.974 & $0.97 I-0.976$ & $<0.00 \mathrm{I}$ & 0.964 & $0.947-0.980$ & $<0.001$ & 0.974 & $0.97 I-0.976$ & $<0.001$ \\
\hline Age, years (continuous variable) & 1.018 & $1.017-1.019$ & $<0.00$ I & 1.014 & $1.003-1.024$ & 0.013 & 1.018 & $1.017-1.019$ & $<0.001$ \\
\hline \multicolumn{10}{|l|}{ Sex } \\
\hline Male & I & & & - & & & I & & \\
\hline Female & 0.927 & $0.895-0.960$ & $<0.00$ I & - & - & - & 0.918 & $0.887-0.951$ & $<0.001$ \\
\hline \multicolumn{10}{|l|}{ Tumor location } \\
\hline Upper thoracic & & & & - & & & I & & \\
\hline Middle thoracic & 1.096 & $0.997-1.130$ & 0.063 & - & - & - & 1.074 & $1.008-1.145$ & 0.027 \\
\hline Lower thoracic & 0.999 & $0.943-1.060$ & 0.984 & - & - & - & 0.999 & $0.942-1.060$ & 0.984 \\
\hline \multicolumn{10}{|l|}{ Tumor histology } \\
\hline Squamous & I & & & I & & & I & & \\
\hline Adenocarcinoma & 1.011 & $0.975-1.049$ & 0.546 & 1.521 & $1.144-2.021$ & 0.004 & 0.999 & $0.963-1.037$ & 0.966 \\
\hline \multicolumn{10}{|l|}{ Grade } \\
\hline Well-differentiated & I & & & - & & & I & & \\
\hline Moderately differentiated & 1.190 & $1.116-1.269$ & $<0.001$ & - & - & - & 1.193 & I.119-1.272 & $<0.001$ \\
\hline Poorly/undifferentiated & 1.409 & $1.323-1.501$ & $<0.00$ I & - & - & - & $\mathrm{I} .404$ & $1.317-1.496$ & $<0.001$ \\
\hline \multicolumn{10}{|l|}{ SEER stage } \\
\hline Localized stage & I & & & I & & & I & & \\
\hline Regional stage & 1.535 & $1.480-1.593$ & $<0.00$ I & 1.261 & $0.94 I-1.690$ & 0.120 & 1.544 & $1.487-1.602$ & $<0.001$ \\
\hline Distant stage & 2.393 & $2.300-2.490$ & $<0.001$ & 1.681 & $1.234-2.29 \mid$ & 0.001 & 2.411 & $2.317-2.509$ & $<0.001$ \\
\hline \multicolumn{10}{|l|}{ Surgery } \\
\hline No & I & & & I & & & I & & \\
\hline Yes & 0.433 & $0.418-0.448$ & $<0.00$ I & 0.507 & $0.382-0.674$ & $<0.001$ & 0.432 & $0.417-0.447$ & $<0.001$ \\
\hline \multicolumn{10}{|l|}{ Radiotherapy } \\
\hline No & I & & & - & & & I & & \\
\hline Yes & 0.679 & $0.659-0.699$ & $<0.00$ I & - & - & - & 0.679 & $0.659-0.699$ & $<0.001$ \\
\hline \multicolumn{10}{|l|}{ Marital status } \\
\hline Married & I & & & - & & & I & & \\
\hline Not married & 1.176 & $1.137-1.216$ & $<0.001$ & - & - & - & I. 172 & $1.133-1.212$ & $<0.001$ \\
\hline
\end{tabular}

Abbreviations: SEER, Surveillance Epidemiology and End Results; HR, hazard ratio; Cl, confidence interval.

Esophagectomy remains the primary therapeutic strategy for EC. In this study, the survival rate of patients undergoing CDS was higher than their counterparts who did not. SEER data revealed that the localized and regional staging was observed in $65.1 \%$ of the Chinese population and $63.8 \%$ of their Caucasian counterparts. The probability of the Chinese race undergoing CDS was $23.2 \%$, which was slightly lower compared with $31.4 \%$ in the Caucasian population;
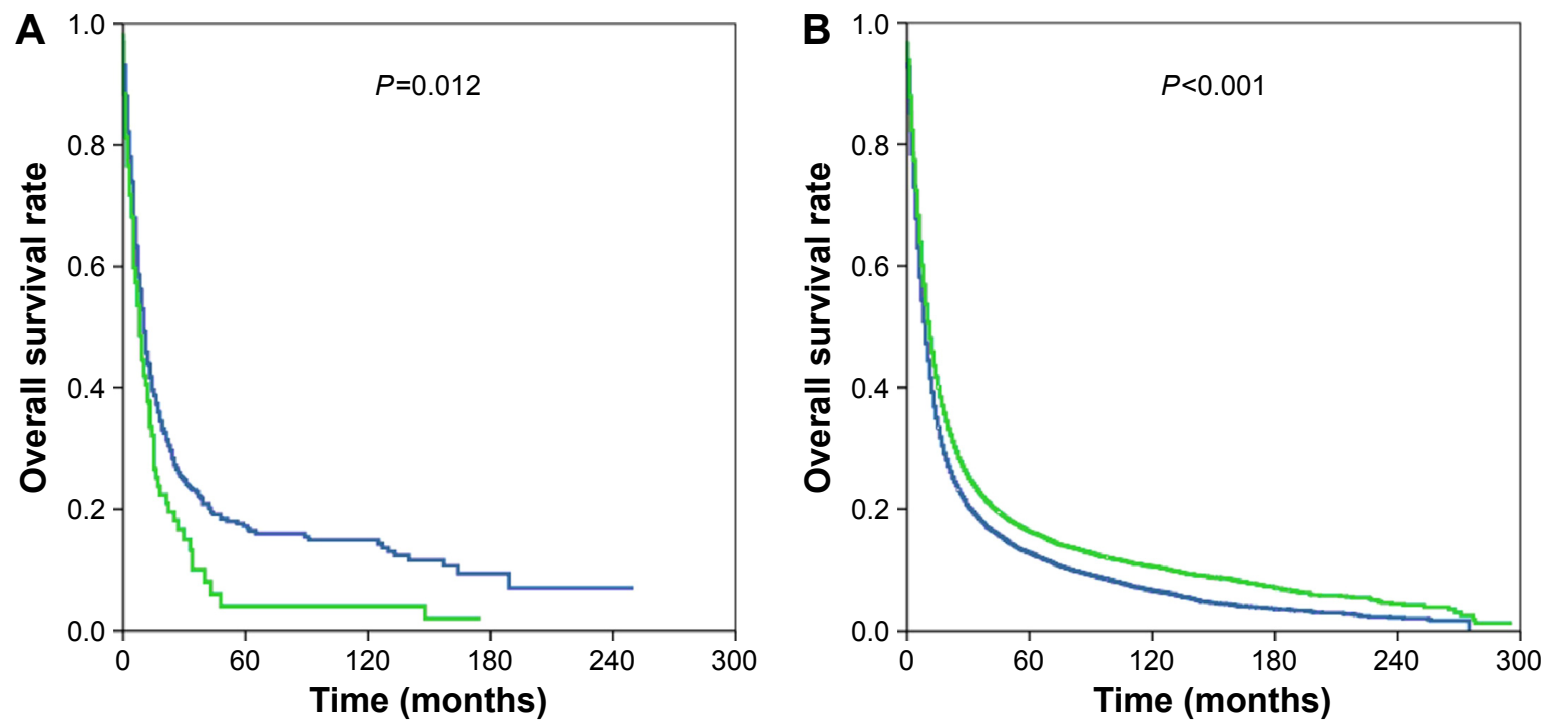

$\neg$ Squamous cell carcinomas $\lrcorner$ Adenocarcinomas

Figure 2 Overall survival of esophageal cancer in Chinese (A) and Caucasian (B) patients by the tumor histology. 
this difference was likely related to the higher surgical difficulty in patients with upper-thoracic EC compared with lower-thoracic EC.

Previous studies have reported that ESCC patients are less likely to present with lymph node metastasis and distant recurrence. ${ }^{20,21}$ In this study, only 89 Chinese, but 8,728 Caucasian patients underwent lymph node dissection. Consequently, it is unreasonable to explicitly compare lymph node metastases between the two populations. The incidence of newly diagnosed distant metastasis was 35\% in the Chinese and $36.2 \%$ in the Caucasian population, with no statistical significance.

In addition, the results of this study showed that the Chinese subgroup with ESCC had a significantly better OS when compared to their Caucasian counterparts, whereas no significant difference in the survival rate was observed between the Chinese and Caucasian patients with EAC. It has been demonstrated that the survival rate of Asian population with endometrial carcinoma, rectal cancer, liver cancer, and non-small-cell lung cancer was higher compared with the non-Hispanic white population. ${ }^{22-25}$ In this study, the survival rate of ESCC patients was higher compared to that of EAC patients in the Chinese population, whereas the survival rate of ESCC and EAC patients did not significantly differ in their Caucasian counterparts. The discrepancy in survival rate among different populations with diverse histologic types probably reflects the following observations. First, there are different risk factors which can induce ESCC and EAC. ${ }^{9,10}$ Second, a genetic difference in EC exists between the Chinese and Caucasian populations. ${ }^{26-33}$ Consequently, a genetic difference might be used to evaluate the clinical prognosis and therapeutic strategy for EC in subsequent investigations.

This study acknowledges several limitations. First, this was a retrospective study. Second, a lack of data in SEER, including chemotherapeutic regimen and dose, local and distant recurrence data, and comorbidities, limited the ability to determine the true etiology in these two races. A strength of this study was that this is the largest study evaluating EC outcomes in Chinese compared to Caucasians residing in the US. Although retrospective reviews should not carry the power of prospective studies, no prospective assessment of the outcome of Chinese and Caucasians in EC exists.

\section{Conclusion}

This study demonstrated that the presenting demographic features, tumor characteristics, and outcomes of EC patients differ between Chinese and Caucasians residing in the US. Chinese patients diagnosed with EAC tend to share clinical features which are similar to their Caucasian counterparts. Chinese patients with ESCC had a better OS than Caucasians. Further studies should be conducted to confirm these conclusions.

\section{Acknowledgments}

This work was supported by grants from the National Natural Science Foundation of China (No: 81402527), the Sci-Tech Office of Guangdong Province (Nos: 2013B021800157, 2013B021800458), and the Natural Science Foundation of Fujian Province (No: 2016J01635).

\section{Disclosure}

The authors report no conflicts of interest in this work.

\section{References}

1. Pohl H, Welch HG. The role of overdiagnosis and reclassification in the marked increase of esophageal adenocarcinoma incidence. $J$ Natl Cancer Inst. 2005;97(2):142-146.

2. Baquet CR, Commiskey P, Mack K, Meltzer S, Mishra SI. Esophageal cancer epidemiology in blacks and whites: racial and gender disparities in incidence, mortality, survival rates and histology. J Natl Med Assoc. 2005;97(11):1471-1478.

3. Greenstein AJ, Litle VR, Swanson SJ, et al. Racial disparities in esophageal cancer treatment and outcomes. Ann Surg Oncol. 2008;15(3): 881-888.

4. Taylor PR, Abnet CC, Dawsey SM. Squamous dysplasia-the precursor lesion for esophageal squamous cell carcinoma. Cancer Epidemiol Biomarkers Prev. 2013;22(4):540-552.

5. Brown LM, Devesa SS. Epidemiologic trends in esophageal and gastric cancer in the United States. Surg Oncol Clin N Am. 2002;11(2):235-256.

6. Arnold M, Soerjomataram I, Ferlay J, Forman D. Global incidence of oesophageal cancer by histological subtype in 2012. Gut. 2015;64(3): 381-387.

7. Rustgi AK, El-Serag HB. Esophageal carcinoma. N Engl J Med. 2014; 371(26):2499-2509.

8. Rubenstein JH, Shaheen NJ. Epidemiology, diagnosis, and management of esophageal denocarcinoma. Gastroenterology. 2015;149(2): 302-317.

9. Zhang Y. Epidemiology of esophageal cancer. World J Gastroenterol. 2013;19(34):5598-5606.

10. Zhang HZ, Jin GF, Shen HB. Epidemiologic differences in esophageal cancer between Asian and Western populations. Chin J Cancer. 2012; 31(6):281-286.

11. Hoeffel EM, Rastogi S, Ouk Kim M, Shahid H. The Asian Population: 2010. Washington, DC: US Census Bureau; 2012.

12. Pineda MD, White E, Kristal AR, Taylor V. Asian breast cancer survival in the US: a comparison between Asian immigrants, US-born Asian Americans and Caucasians. Int J Epidemiol. 2001;30(5):976-982.

13. Surveillance, Epidemiology, and End Results (SEER) Program. SEER*Stat Database: Incidence - SEER 18 Regs Research Data + Hurricane Katrina Impacted Louisiana Cases, Nov 2014 Sub (1973-2012 varying) - Linked To County Attributes - Total US, 1969-2013 Counties. National Cancer Institute, DCCPS, Surveillance Research Program, Surveillance Systems Branch, released April 2015, based on the November 2014 submission. Available from: www.seer.cancer.gov. Accessed November 14, 2015.

14. He Z, Wu S, Li Q, Lin Q, Xu J. Use of the metastatic lymph node ratio to evaluate the prognosis of esophageal cancer patients with node metastasis following radical esophagectomy. PLoS One. 2013;8(9):e73446. 
15. Huang W, Li B, Gong H, et al. Pattern of lymph node metastases and its implication in radiotherapeutic clinical target volume in patients with thoracic esophageal squamous cell carcinoma: a report of 1077 cases. Radiother Oncol. 2010;95(2):229-233.

16. Chen XL, Chen TW, Fang ZJ, et al. Patterns of lymph node recurrence after radical surgery impacting on survival of patients with pT1-3N0M0 thoracic esophageal squamous cell carcinoma. J Korean Med Sci. 2014; 29(2):217-223.

17. Lagergren J, Bergström R, Lindgren A, Nyrén O. Symptomatic gastroesophageal reflux as a risk factor for esophageal adenocarcinoma. N Engl J Med. 1999;340(11):825-831.

18. Liu S, Dai JY, Yao L, et al. Esophageal adenocarcinoma and its rare association with Barrett's esophagus in Henan, China. PLoS One. 2014; 9(10): 110348.

19. Liu SZ, Wang B, Zhang F, et al. Incidence, survival and prevalence of esophageal and gastric cancer in Linzhou city from 2003 to 2009. Asian Pac J Cancer Prev. 2013;14(10):6031-6034.

20. Mariette C, Finzi L, Piessen G, Van Seuningen I, Triboulet JP. Esophageal carcinoma: prognostic differences between squamous cell carcinoma and adenocarcinoma. World J Surg. 2005;29(1):39-45.

21. Siewert JR, Ott K. Are squamous and adenocarcinomas of the esophagus the same disease? Semin Radiat Oncol. 2007;17(1):38-44.

22. Soo RA, Loh M, Mok TS, et al. Ethnic differences in survival outcome in patients with advanced stage non-small cell lung cancer: results of a meta-analysis of randomized controlled trials. J Thorac Oncol. 2011; 6(6):1030-1038.

23. Le H, Ziogas A, Taylor TH, Lipkin SM, Zell JA. Survival of distinct Asian groups among colorectal cancer cases in California. Cancer. 2009; 115(2):259-270.
24. Artinyan A, Mailey B, Sanchez-Luege N, et al. Race, ethnicity, and socioeconomic status influence the survival of patients with hepatocellular carcinoma in the United States. Cancer. 2010;116(5):1367-1377.

25. Mahdi H, Schlick CJ, Kowk LL, Moslemi-Kebria M, Michener C. Endometrial cancer in Asian and American Indian/Alaskan Native women: tumor characteristics, treatment and outcome compared to non-Hispanic white women. Gynecol Oncol. 2014;132(2):443-449.

26. Wang LD, Zhou FY, Li XM, et al. Genome-wide association study of esophageal squamous cell carcinoma in Chinese subjects identifies susceptibility loci at PLCE1 and C20orf54. Nat Genet. 2010;42(9): 759-763.

27. Abnet CC, Freedman ND, Hu N, et al. A shared susceptibility locus in PLCE1 at 10q23 for gastric adenocarcinoma and esophageal squamous cell carcinoma. Nat Genet. 2010;42(9):764-767.

28. Wu C, Hu Z, He Z, et al. Genome-wide association study identifies three new susceptibility loci for esophageal squamous-cell carcinoma in Chinese populations. Nat Genet. 2011;43(7):679-684.

29. Cheung WY, Liu G. Genetic variations in esophageal cancer risk and prognosis. Gastroenterol Clin North Am. 2009;38(1):75-91.

30. Hiyama T, Yoshihara M, Tanaka S, Chayama K. Genetic polymorphisms and esophageal cancer risk. Int J Cancer. 2007;121(8):1643-1658.

31. Liu CY, Wu MC, Chen F, et al. A large-scale genetic association study of esophageal adenocarcinoma risk. Carcinogenesis. 2010;31(7): 1259-1263.

32. Jain M, Kumar S, Lal P, Tiwari A, Ghoshal UC, Mittal B. Role of GSTM3 polymorphism in the risk of developing esophageal cancer. Cancer Epidemiol Biomarkers Prev. 2007;16(1):178-181.

33. Gao YB, Chen ZL, Li JG, et al. Genetic landscape of esophageal squamous cell carcinoma. Nat Genet. 2014;46(10):1097-1102. 


\section{Supplementary materials}

Table SI Univariate Cox analysis of overall survival of patients with esophageal squamous cell carcinoma and esophageal adenocarcinoma

\begin{tabular}{|c|c|c|c|c|c|c|}
\hline \multirow[t]{2}{*}{ Characteristic } & \multicolumn{3}{|c|}{ ESCC } & \multicolumn{3}{|l|}{ EAC } \\
\hline & HR & $95 \% \mathrm{Cl}$ & $P$-value & HR & $95 \% \mathrm{Cl}$ & $P$-value \\
\hline Years of study (continuous variable) & 0.990 & $0.988-0.993$ & $<0.001$ & 0.981 & $0.979-0.984$ & $<0.001$ \\
\hline Age, years (continuous variable) & 1.018 & $1.016-1.020$ & $<0.001$ & 1.019 & $1.018-1.021$ & $<0.001$ \\
\hline \multicolumn{7}{|l|}{ Sex } \\
\hline Male & I & & & I & & \\
\hline Female & 0.920 & $0.885-0.957$ & $<0.001$ & 1.136 & $1.091-1.182$ & $<0.001$ \\
\hline \multicolumn{7}{|l|}{ Tumor location } \\
\hline Upper thoracic & I & & & I & & \\
\hline Middle thoracic & 0.974 & $0.922-1.028$ & 0.340 & 1.035 & $0.909-1.178$ & 0.605 \\
\hline Lower thoracic & 0.952 & $0.90 \mathrm{I}-\mathrm{I} .007$ & 0.085 & 0.849 & $0.75 I-0.958$ & 0.008 \\
\hline \multicolumn{7}{|l|}{ Grade } \\
\hline Well-differentiated & I & & & 1 & & \\
\hline Moderately differentiated & 1.331 & $1.210-1.464$ & $<0.001$ & 1.307 & $1.219-1.402$ & $<0.001$ \\
\hline Poorly/undifferentiated & 1.470 & $1.336-1.616$ & $<0.001$ & 1.776 & $1.659-1.903$ & $<0.001$ \\
\hline \multicolumn{7}{|l|}{ SEER stage } \\
\hline Localized stage & I & & & I & & \\
\hline Regional stage & 1.181 & $1.121-1.243$ & $<0.001$ & 1.522 & $1.46 \mathrm{I}-1.586$ & $<0.001$ \\
\hline Distant stage & 2.160 & $2.046-2.28 I$ & $<0.001$ & 3.471 & $3.334-3.614$ & $<0.001$ \\
\hline \multicolumn{7}{|l|}{ Surgery } \\
\hline No & 1 & & & 1 & & \\
\hline Yes & 0.482 & $0.458-0.506$ & $<0.001$ & 0.333 & $0.322-0.344$ & $<0.001$ \\
\hline \multicolumn{7}{|l|}{ Radiotherapy } \\
\hline No & 1 & & & 1 & & \\
\hline Yes & 0.674 & $0.647-0.701$ & $<0.001$ & 0.876 & $0.85 I-0.90 I$ & $<0.001$ \\
\hline \multicolumn{7}{|l|}{ Marital status } \\
\hline Married & 1 & & & 1 & & \\
\hline Not married & 1.083 & $1.035-1.132$ & 0.001 & 1.091 & $1.054-1.129$ & $<0.001$ \\
\hline \multicolumn{7}{|l|}{ Ethnicity } \\
\hline Chinese & 1 & & & 1 & & \\
\hline Caucasian & 1.202 & $1.075-1.344$ & 0.001 & 0.725 & $0.577-0.911$ & 0.006 \\
\hline
\end{tabular}

Abbreviations: SEER, Surveillance Epidemiology and End Results; HR, hazard ratio; Cl, confidence interval; ESCC, esophageal squamous cell carcinoma; EAC, esophageal adenocarcinoma. 
Table S2 Multivariate Cox analysis of overall survival of patients with esophageal squamous cell carcinoma and esophageal adenocarcinoma

\begin{tabular}{|c|c|c|c|c|c|c|}
\hline \multirow[t]{2}{*}{ Characteristic } & \multicolumn{3}{|c|}{ ESCC } & \multicolumn{3}{|l|}{ EAC } \\
\hline & HR & $95 \% \mathrm{Cl}$ & $P$-value & HR & $95 \% \mathrm{Cl}$ & $P$-value \\
\hline Years of study (continuous variable) & 0.979 & $0.975-0.982$ & $<0.001$ & $0.97 I$ & $0.968-0.974$ & $<0.001$ \\
\hline Age, years (continuous variable) & 1.017 & $1.014-1.019$ & $<0.001$ & 1.018 & $1.017-1.020$ & $<0.001$ \\
\hline \multicolumn{7}{|l|}{ Sex } \\
\hline Male & 1 & - & - & 1 & - & - \\
\hline Female & 0.870 & $0.828-0.915$ & $<0.001$ & 0.972 & $0.925-1.022$ & 0.273 \\
\hline \multicolumn{7}{|l|}{ Tumor location } \\
\hline Upper thoracic & - & - & - & I & - & - \\
\hline Middle thoracic & - & - & - & 1.033 & $0.880-1.213$ & 0.692 \\
\hline Lower thoracic & - & - & - & 0.902 & $0.776-1.050$ & 0.183 \\
\hline \multicolumn{7}{|l|}{ Grade } \\
\hline Well-differentiated & I & - & - & 1 & - & - \\
\hline Moderately differentiated & 1.213 & $1.085-1.356$ & 0.001 & 1.167 & $1.079-1.262$ & $<0.00 \mathrm{I}$ \\
\hline Poorly/undifferentiated & 1.212 & $1.084-1.355$ & 0.001 & 1.491 & $1.380-1.611$ & $<0.00 \mathrm{I}$ \\
\hline \multicolumn{7}{|l|}{ SEER stage } \\
\hline Localized stage & I & - & - & 1 & - & - \\
\hline Regional stage & 1.355 & $1.276-1.438$ & $<0.001$ & 1.633 & $1.556-1.715$ & $<0.001$ \\
\hline Distant stage & 1.995 & $1.869-2.130$ & $<0.001$ & 2.651 & $2.52 I-2.788$ & $<0.00 \mathrm{I}$ \\
\hline \multicolumn{7}{|l|}{ Surgery } \\
\hline No & I & - & - & I & - & - \\
\hline Yes & 0.445 & $0.417-0.475$ & $<0.001$ & 0.427 & $0.409-0.446$ & $<0.001$ \\
\hline \multicolumn{7}{|l|}{ Radiotherapy } \\
\hline No & I & - & - & 1 & - & - \\
\hline Yes & 0.563 & $0.534-0.594$ & $<0.001$ & 0.734 & $0.709-0.761$ & $<0.00$ I \\
\hline \multicolumn{7}{|l|}{ Marital status } \\
\hline Married & I & - & - & I & - & - \\
\hline Not married & 1.190 & $1.125-1.260$ & $<0.001$ & 1.151 & I.107-I.203 & $<0.001$ \\
\hline \multicolumn{7}{|l|}{ Ethnicity } \\
\hline Chinese & I & - & - & I & - & - \\
\hline Caucasian & 1.330 & $1.159-1.527$ & $<0.00$ I & 0.853 & $0.642-1.132$ & 0.271 \\
\hline
\end{tabular}

Note: -, No significance of the tumor location in the univariate Cox analysis.

Abbreviations: SEER, Surveillance Epidemiology and End Results; HR, hazard ratio; CI, confidence interval; ESCC, esophageal squamous cell carcinoma; EAC, esophageal adenocarcinoma.

\section{Publish your work in this journal}

OncoTargets and Therapy is an international, peer-reviewed, open access journal focusing on the pathological basis of all cancers, potential targets for therapy and treatment protocols employed to improve the management of cancer patients. The journal also focuses on the impact of management programs and new therapeutic agents and protocols on patient perspectives such as quality of life, adherence and satisfaction. The manuscript management system is completely online and includes a very quick and fair peer-review system, which is all easy to use. Visit http://www.dovepress.com/testimonials.php to read real quotes from published authors. 